\title{
A LÍNGUA NA LÍNGUA DO POETA: O PRÓPRIO DA LÍNGUA
}

\author{
ELIANA DE ALMEIDA ${ }^{1}$ \\ Universidade do Estado de Mato Grosso, Programa de Pós-Graduação em Linguística \\ Departamento de Letras - Pontes e Lacerda (MT), Brasil \\ tofinhodyahoo.com.br \\ VANISE MEDEIROS ${ }^{2}$ \\ Universidade Federal Fluminense \\ Programa de Pós-Graduação em Estudos de Linguagem \\ Gragoatá, s/n. Niterói (RJ), Brasil \\ $\underline{\text { vanisegmeyahoo.com.br }}$
}

\begin{abstract}
Resumo. A literatura se constitui a partir de rituais que instauram uma memória na língua: memória na sintaxe, nas repetições; memória que dá forma e formato ao texto e que se inscreve ainda nas suas bordas (titulo, epígrafes, notas, e, entre outras, glossários). Ritual este que inscreve o dentro e o fora do texto; e que fura. Com o poema "Glossário de transnominações em que não se explicam algumas delas (nenhumas) ou menos", de Manoel de Barros estamos diante de uma quebra do ritual glossário. Os diferentes chãos deste artigo dizem da análise: das retomadas teóricas, a partir do que problematizamos a escrita literária, como ritual discursivo de dizer, indo aos chãos que conduziram, de modo especial, refletir sobre a língua, ancoradas em Foucault (1996); Pêcheux (1990) e Auroux (1998).
\end{abstract}

Palavras-chave: língua; ritual discursivo; glossário; literatura; escrita.

\begin{abstract}
The literature is constituted from rituals that establish a memory in the language: memory in the syntax, in the repetitions; memory that gives form and format to the text and that still inscribes in its borders (title, epigraphs, notes, and, among others, glossaries). This ritual that inscribes the inside and the outside of the text; and that sticks. With the poem "Glossary of transnominations in which some of them (none) or less are not explained," we are faced with a break in the glossary ritual. The different floors of this article refer to the analysis of theoretical retakes, from which we problematize literary writing, as a discursive ritual of saying, going to the floors that led, especially, to reflect on the language, anchored in Foucault (1996); Pêcheux (1990) and Auroux (1998).
\end{abstract}

Keywords: language; discursive ritual; glossary; literature; writing.

\footnotetext{
${ }^{1}$ Professora da Universidade do Estado de Mato Grosso, UNEMAT. Coordenadora do Grupo de Pesquisa Cartografias da Linguagem.

2 Doutora associada do Instituto de Letras da Universidade Federal Fluminense; uma das coordenadoras do Laboratório Arquivos do Sujeito (LAS/UFF). Bolsista produtividade 2 do CNPq e CNE (FAPERJ).
} 


\section{CHÃO}

O chão é um ensino

Manoel de Barros

Neste artigo, trazemos para leitura o Glossário de transnominações em que não se explicam algumas delas (nenhumas) ou menos, de Manoel de Barros (1916-2014). Um glossário-poema ${ }^{3}$ com suas glosas, repetições, palavras sob palavras, regido sob as configurações da literatura que, enquanto linguagem, o leva aos últimos limites de se significar como ritual (COMPAGNON, 1996). Propomos com ele a compreensão de um certo ritual discursivo: um espaço de dizer definido e configurado na língua, no modo de dizer; um lugar de textualização ritualizada de discursos em que se especifica o que pode ser dito e se define o modo próprio desse dizer (PÊCHEUX, 1990; 1997; FOUCAULT, 1996; 2005; 2006).

O glossário-poema, na poesia de Manoel de Barros, pode ser pensado como ritual de uma escrita em que citação, glosa, palavra sob palavra denunciam palavras outras e anteriores, pondo em cena e em suspensão a alteridade que o constitui. Propusemos a leitura da poesia de Manoel de Barros, presente na obra Arranjos para assobio (1998), como um texto outro ao propor, como glossário, a definição de palavras pela indefinição, e o pensamos no ritual de dizer pela poesia. Definições pela poesia.

Os diferentes chãos, com que nomeamos as partes deste artigo e que nos chegaram a partir das leituras do poema, dizem do nosso percurso de formulação: desde as retomadas teóricas, a partir do que problematizamos sobre a escrita, como um ritual discursivo de dizer, indo aos chãos que nos conduzem, de modo especial, à compreensão do glossário-poema enquanto um ritual literário de dizer. Efeitos do comentário, conforme Foucault, pondo em movimento o acontecimento - da ordem da repetição - e o acaso - da ordem da diferença.

\section{OUTROS CHÃOS}

Aquilo que ensina de chão Manoel de Barros

Ao considerar que a linguagem humana não seja diretamente ligada à especificidade do canal-áudio-oral, Auroux (1998, p. 63-66) confere à escrita o lugar de suporte transposto, definindo-a na sua relação com os elementos da língua mesma e não com os do mundo. A escrita é, para o autor, uma das formas de representação das linguagens naturais, tornando possível a reflexão linguística, na civilização ocidental, pela alteridade que lhe é própria. Alteridade esta que se apresenta, conforme Auroux (1998, p. 77), à medida que a escrita vai transpondo, sob sua ordem, outras formas de linguagem, pois que vão ficando os restos, os vestígios das formas primeiras (da oralidade). A propósito da escrita, vale dizer, nos termos de Auroux, que uma

\footnotetext{
${ }^{3}$ Esta denominação foi por nós cunhada para o poema de Manoel de Barros: um poema que se estrutura sob a forma de glossário.
} 
transposição de suportes só é possível porque a substância, o conteúdo, não é essencial à linguagem.

Do ponto de vista discursivo, Orlandi (1999, p. 7-21) não opõe escrita e oralidade, conforme configurada numa tipologia, por considerar de maior importância os diferentes gestos de interpretação que escrita/oralidade produzem. No entanto, considera que, no interior do imaginário social, essa tipologia tenha sua eficácia, e afirma a escrita como estruturante das relações sociais, nas sociedades de escrita. Consideramos da afirmação de Auroux, de que a "memória das sociedades orais não funciona da mesma maneira que a das sociedades grafematizadas" (AUROUX,1998, p. 70), o que nos leva a observar uma estreita relação com o que, discursivamente, Orlandi propõe sobre a escrita, ao afirmar "a escrita especifica a natureza da memória" (ORLANDI, 1999, p. 7-21). Memória essa que define para o sujeito, em seus processos de individualização, um saber elaborado pelo trabalho simbólico, sócio-histórico, e não apenas o saber da urgência técnica para um sujeito pragmático. A escrita se inscreve assim nos estudos discursivos da linguagem como o espaço de dizer da relação entre língua/ela mesma e língua/sujeito.

Em $A$ ordem do discurso, Foucault trata do comentário como uma forma de controle exercida no interior do discurso e por ele mesmo, cujos procedimentos funcionam "a título de princípios de classificação, de ordenação, de distribuição, etc." (FOUCAULT, 1996, p. 21). O autor submete o comentário ao acontecimento e o acaso, outra dimensão do discurso, logo, o comentário supõe o repetível (previsível) ${ }^{4}$, o mesmo e o acaso, da ordem do novo, da diferença, da ruptura, concomitantemente. À medida que a escrita permite, por um lado, construir indefinidamente o que seria da ordem do novo, o diferente, sempre reatualizável, de outro lado, permite a repetição, ao referir ao texto primeiro. Com isso, Foucault atesta o paradoxo próprio do comentário, ao afirmar que do comentário se desloca sempre, mas dele não se escapa nunca, como reitera ao afirmar: "dizer pela primeira vez aquilo que, entretanto, já havia sido dito e repetir incansavelmente aquilo que, no entanto, não havia jamais sido dito" (idem, p. 25).

O comentário refere-se então, a propósito da escrita, à remissão aos textos religiosos, jurídicos, literários, científicos, etc., que funcionam, conforme afirma Foucault, como "narrativas maiores que se contam, se repetem e se fazem variar; fórmulas, textos, conjuntos ritualizados que se narram, conforme circunstâncias bem determinadas." (ibidem p. 22). Tal funcionamento discursivo da escrita, em que o mesmo é posto em movimento pelas formulações que o reatualizam, mostra o paradoxo entre o acontecimento e o acaso, próprio do comentário, conforme o autor, na formulação "o novo não está no que é dito, mas no acontecimento a sua volta" (ib., p. 26).

A conferência ${ }^{5}$ inédita de Michel Foucault, "Linguagem e Literatura", trata da ordem do discurso literário, quando afirma a literatura não ser tão antiga quanto a linguagem. Assim, propõe o questionamento das obras de Dante, Cervantes ou Eurípedes como literárias, e, enquanto tais, questiona o fato de serem impostas como parte da nossa literatura, afirmando o gesto como uma "relação [de importância] que só a nós diz respeito" (FOUCAULT, 2005, p. 139). Ao considerar que a literatura grega ou latina não tivera jamais existido, Foucault (2005, p. 139) o atesta pela impossibilidade, à época, de

\footnotetext{
4 "Não há sociedade onde não existam narrativas maiores que se contam, se repetem e se fazem variar; fórmulas, textos, conjuntos ritualizados de discursos que se narram, conforme circunstâncias bem determinadas [...]" (FOUCAULT, 1996, p. 22).

5 Pronunciada na Facultés Universitaires Saint-Louis, Bruxelas, em março de 1964, publicada na obra Foucault, a filosofia e a literatura (2005), organizada por Roberto Machado e editada pela Jorge Zahar.
} 
uma memória literária, e então demarca o surgimento da literatura coincidindo com o modo de ser da linguagem, possível no início do século XIX, ao descrever as relações entre a escrita literária e os livros primeiros, o texto literário e a memória discursiva que o constitui. A literatura supõe assim a memória da língua. Para o autor, a literatura consiste "numa linguagem que repete o que foi dito e que, por causa dessa repetição, apaga tudo o que foi dito e, ao mesmo tempo, o aproxima o mais possível de si mesma para recuperar a própria essência" (FOUCAULT, 2005, p. 153). A essência do texto poético, literário, seria o funcionamento próprio da linguagem sobre si mesma.

Nesse movimento de repetição/diferença, a literatura, enquanto um modo de ser da linguagem, não se configura a formas e formatos rígidos para a sua textualização, ao definir-se como, a partir de Foucault, uma "espécie de ritual prévio que traça o espaço das palavras" (FOUCAULT, 2005, p. 142). Um ritual prévio, instaurado por um modo literário de dizer, que se define dentre os da sociedade literária de discurso. Assim, um ritual próprio de dizer pela escrita o discurso do Outro, à medida que tal ritual captura o escritor pelo/no curso de suas palavras.

Não obstante aos efeitos do ritual, no trabalho de naturalização dos sentidos da literatura, ao fixar modelos, produzir repetição, vale dizer que, ao mesmo tempo, o ritual desfaz-se no lapso, no furo, como afirma Pêcheux: "o deslize, a falha e a ambiguidade são constitutivos da língua, e é por aí que a questão do sentido surge do interior da sintaxe". (PÊCHEUX, 1997, p. 62). Pêcheux considera, a partir de Canguilhen, que se o homem é capaz de jogar sobre o sentido, é porque, por essência, a própria língua encobre esse jogo.

Em “Delimitações, inversões, deslocamentos", Pêcheux (1990, p. 7-24) supõe as ideologias dominantes e dominadas como que indivisas no interior do discurso, como um lugar de sem fronteiras, cujo efeito de separação se liga ao fato de que o indivíduo é interpelado em sujeito, levando até as últimas consequências a interpelação ideológica como um ritual pelo reconhecimento de que não há ritual sem falha, dado que a contradição passa a ser constitutiva do discurso. $O$ autor supõe o surgimento do novo na quebra de rituais, na movência dessas fronteiras discursivas e afirma:

[...] o frágil questionamento de uma ordem, a partir da qual o lapso pode tornar-se discurso de rebelião, o ato falho, de motim e de insurreição, o momento imprevisível em que uma série heterogênea de efeitos individuais entra em ressonância e produz um acontecimento histórico, rompendo o círculo da repetição. (PÊCHEUX, p. 1990, 17)

Se a literatura, como vimos a partir de Foucault, funciona como essa linguagem infinita sob a forma do comentário em rituais próprios, tematizando e formulando pela/na repetição de si mesmos, pelo controle e pela administração de uma sociedade do discurso literário, ao mesmo tempo, é também enquanto linguagem que a literatura expõe-se pela/na falha ao estilhaçamento do signo, à quebra do ritual mesmo, conforme Pêcheux, para a produção do novo. 


\title{
CHÃO PALAVRA
}

Espécie de vazadouro para contradições Manoel de Barros

\begin{abstract}
Glossário de transnominações em que não se explicam algumas delas (nenhumas) ou menos ${ }^{6}$ nos avisa o poeta jogando com um certo fazer escrita. Fiquemos por ora com glossário: glosas sobre a palavra, nos revela a etimologia da palavra - a palavra glossário, do século XVI, advém de glosa, do século XII. Por glosa, lemos em Dubois (1991, p. 308) anotações em manuscritos acima ou à margem da palavra -, que nos leva à escrita medieval: comentário, como sabemos com Compagnon (1996) e como trazemos com Foucault (1996). Texto sobre texto; palavra sobre palavra(s). Dobras.
\end{abstract}

Em O trabalho da citação, Compagnon nos fala que citar nasce do grifo, da marca da leitura sobre a palavra ou sobre o texto. Encontro com a palavra e na palavra; encontro com o texto e no texto (ele nos lembra, em nota, que citar em espanhol tem também o sentido de encontro). Encontro que se faz movimento pelo contato, é ele a nos dizer, e pelo que dali se depreende para se acomodar em outro lugar. Objeto outro agora tornado seu ainda que como outro. No grifo, citação, glosa e glossário se encontram: advêm da leitura - para usar uma imagem dele: cobrem o texto de olhos - e se tornam escrita. Olhos nos textos; olhos, que, recuperando Compagnon, tanto se defendem contra o olhar outro quanto se mostram ao olhar outro. Pontos de contato sobre o texto que, no atrito, ganham movência. Pontos de corte e de sutura, podemos dizer dos três. Pontos de fuga e contenção. Pontos do outro e do Outro.

O glossário, tal como a citação, denuncia um texto outro, um texto anterior; ambos se constituem na alteridade e a expõem. Com Auroux (1992), sabemos que os glossários nasceram da alteridade. Aí alteridade remete teoricamente ao outro; não ao Outro. Com ele, ficamos sabendo que os glossários se prestavam à leitura de uma língua outra ou de textos antigos a serem decifrados; vinham à margem do texto ou no meio deles. Em poucas palavras, a alteridade tange, então, ao outro que lhe antecede (texto ou língua) e que se desconhece (texto ou língua). Os glossários, textos outros, eram, portanto, tomados como servindo à elucidação do desconhecido.

Com Authier-Revuz (1990), a questão da alteridade, sob a forma de uma reflexão sobre a heterogeneidade, assume outra dimensão. É já clássica a sua explicação de que "sempre sob as palavras, 'outras palavras' são ditas" (Authier-Revuz, 1990, p. 28; aspas da autora); ou seja, de que as palavras são desde sempre advindas do Outro, com maiúsculas, anterior e não localizável, que atravessa todo e qualquer discurso e que constitui o sujeito: heterogeneidade constitutiva. Com essa, que constitui o dizer, AuthierRevuz nos diz negociar uma outra, da ordem da representação e que assegura ao sujeito sua separação em relação ao dizer outro (ilusão necessária para se fazer um em seu dizer/ser). Essa outra heterogeneidade (mostrada) demarca fronteiras nos dizeres que seriam do um e do outro. A citação, a glosa e o glossário aí se situam. Configuram, então, fronteiras que garantiriam ao sujeito a tranquilidade de supor que, jogando com as palavras de Authier-Revuz, o que diz vá ou não de si. Mas não se pode deixar de assinalar que, com elas, se escamoteia a heterogeneidade constitutiva, o Outro. E, assim, no caso, as paradas sobre a palavra ou texto de que resultam as citações, glosas e glossários, para

\footnotetext{
${ }^{6}$ Devemos a Alexandre Zanella a alegria do encontro com este poema de Manoel de Barros.
} 
além de tomadas como da ordem da elucidação de um desconhecido, são pensadas como lugares que denunciam o trabalho de um "eu' que se supõe "eu" com o que pode instaurar seu(s) outro(s). Citação, glosa e glossário passam a serem compreendidos, a partir de Authier-Revuz, como lugar de embate do sujeito na língua que o constitui. Recuperando Auroux, podemos dizer que os glossários se configuram como uma reflexão metalinguística sobre o outro que resulta numa reflexão sobre si.

Se pudemos aproximar os três, é preciso dizer algumas das suas distinções; afinal, funcionam diferentemente. Se a citação ou a glosa se acomodam à linha da escritura; o glossário transborda, extravasa, ultrapassa as fronteiras e se faz corpo em outro espaço. Se a citação, conforme Compagnon, se introduz como enxerto privilegiado - lugar de reconhecimento - que se integra ao texto e a ele serve, sobre a glosa, lendo AuthierRevuz, diremos que funciona como indício de algum descompasso: é preciso voltar à palavra, é preciso redizer, bem-dizer, maldizer, desdizer... Do glossário talvez possamos dizer que funciona como "vazadouro de sentidos", para usarmos o que aprendemos com o poeta, na ilusão da saturação, como aponta Orlandi (2007) sobre a nota de pé de página. Espaço contraditório: é por se apresentar como espaço de explicação, definição, de se fazer como lugar de contenção dos sentidos, que expõe, no gesto de apreensão do sentido, a possibilidade de que o sentido poderia ser outro. Mas nosso glossário não cai neste engodo: as "transnominações... não se explicam algumas delas (nenhumas) ou menos". Ao contrário, com ele joga. Se os glossários ou as notas não permitem, de novo nos valendo de Compagnon, nenhum remorso, uma vez que neles tudo estaria dito (e aí reside a ilusão do desvendamento, do deciframento que se ancora no um); não é caso do poemaglossário aqui em foco. Estamos não na língua dos gramáticos, mas nas "rupturas do ordinário da língua de que é feita a poesia" (LEMOS, 2009, p. 208). Não no espaço do cálculo, da lógica, da regra, do sistema, mas naquele que sustenta o furo, a falha, naquele que suporta o desejo e o gozo, de que fala Milner (1987), ao indicar um real da língua que o linguista foraclui, mas não, ousamos dizer, nosso poeta.

\section{O CHÃO VIÇAVA NO OLHO}

cada pássaro governava sua árvore Manoel de Barros

A literatura propõe a quebra de rituais na escrita literária sob diferentes formas, como veremos no caso de Manoel de Barros, antes de falar do seu glossário-poema. De início, destacamos o fato de que três de suas obras (Fig. 1), Memórias Inventadas - a Infância (2003), Memórias Inventadas - a Segunda Infância (2006) e Memórias Inventadas - a Terceira Infância (2008), fogem a princípio às configurações do livro, pois que as poesias se apresentam em páginas avulsas, dentro de uma caixa. Dobrada ao meio, a folha de rosto traz o título da poesia e, no seu verso, a iluminura, antecedendo o texto poético que vem simetricamente exposto à terceira página.

Cada poesia é um belo encarte, sendo que o conjunto fica acomodado em outro encarte, externo. Dobras que se redobram e se desdobram. O texto ganha outros corpos, outras vitrines. Essa proposta de edição impõe procedimentos específicos de leitura, visto que a prática de virar a página é substituída pela escolha do encarte a ser lido. Olhos e mão. No entanto, no encarte externo preservam-se todas as notificações do ritual de uma obra literária: à página de frente, uma iluminura, o título da obra, os nomes do escritor e 
da desenhista, a editora; e, no verso, as informações editoriais e a ficha catalográfica. $\mathrm{O}$ ritual do encarte opera com a diferença, em relação ao livro, no entanto, as inscrições que o circunscrevem ao discurso literário informam, orientam, controlam, administram os sentidos próprios desse ritual.

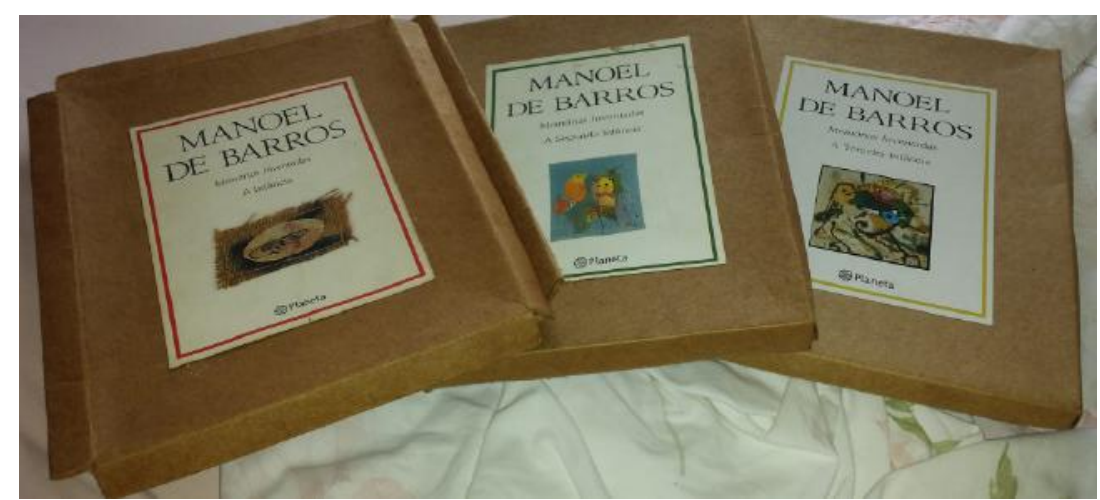

Fig. 1.

O gesto de editar os encartes das caixinhas, sob o ritual literário de dizer, propõe para a literatura trabalhar a sua relação com outras artes, deslocando em sua obra o espaço consagrado ao livro para outras formas de edição da poesia.

Ainda no que concerne ao aspecto material de editoração, à quebra de rituais, tomamos a obra Exercícios de ser criança (1999), publicada pela Editora Salamanca. Trata-se de uma obra, livro tamanho grande, marcada pelos modos de ilustração, cujos bordados coloridos dividem esteticamente a página e o texto, apagando a predominância de um sobre o outro. Ou seja, a ilustração e o texto jogam entre si, se complementando na página, como se um fizesse referência ao outro. É uma obra que opera com diferentes instâncias da transposição de suporte, nos termos de Auroux, visto que, os belos bordados de Antônia Zulma Diniz, Ângela e Marilu são fotografados, e tais fotografias são tomadas como ilustrações do texto poético, por Martha e Sávia Dumont. No que concerne à materialidade simbólica da escrita, o jogo entre ilustração e texto se conjuga, se complementa, visto que, nas formulações "O menino era ligado em despropósitos/. [...] /Você vai encher os vazios com as suas peraltagens e algumas pessoas vão te amar por seus despropósitos/", as palavras despropósitos e peraltagens não são escritas tipograficamente, como no comum dos textos, mas escritas e representadas pelo/em bordado fotografado. Ou seja, essas palavras, especificamente, são bordadas bordados. São textualizações do múltiplo, da diferença, da ruptura.

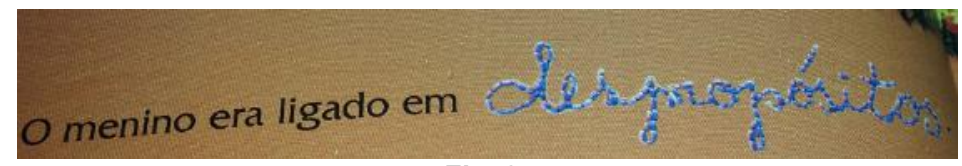

Fig. 2. 


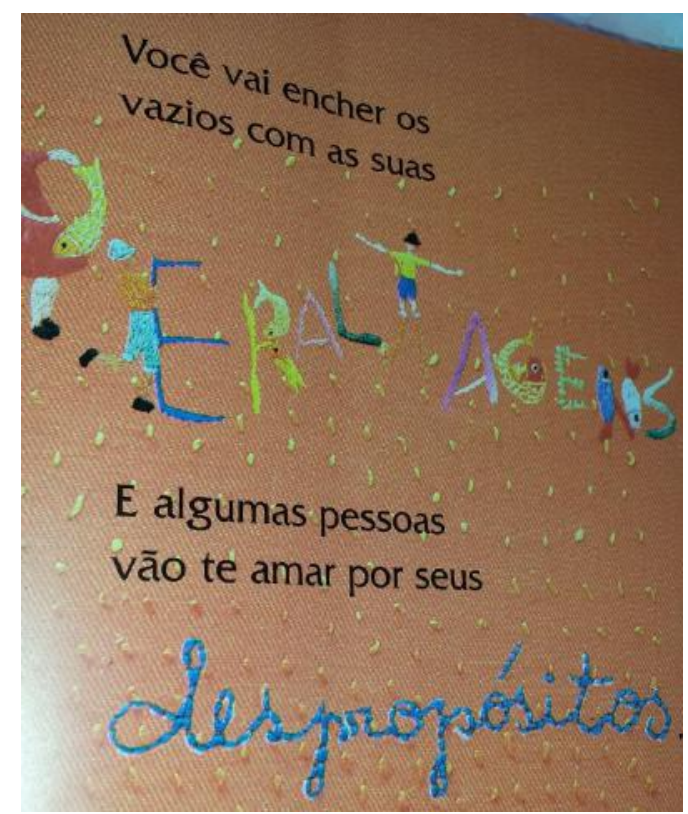

Fig. 3.

Não seria trivial considerar a relação entre esses termos - despropósitos e peraltagens - e o título da obra Exercícios de ser criança, funcionando como sendo esses termos a definição do ser criança. Esse gesto de escrita, na obra literária, denuncia/materializa a peraltice e os despropósitos do escritor, à medida que introduz, pelo bordado, as palavras do texto poético, produzindo o furo e quebrando a ordem do ritual de escrita literária. Esses termos são palavras do texto; são representações de bordado - uma materialidade simbólica outra - promovendo a (des)unidade textual. É com a palavra representada como bordado que o poeta Manoel de Barros, como criança travessa, arteira, fura a ordem tradicional da escrita literária. E, assim transgredindo, materializa a palavra escrita nessa conjugação entre fotografia, bordado, grafia e letra.

Os rituais de escrita se quebram em Manoel de Barros, como em Concerto a céu aberto para solos de ave (2004), na poesia Cadernos de Apontamentos, Fragmento $\mathrm{XXIV}$, em que o escritor brinca, jogando entre diferentes materialidades simbólicas, a letra tipográfica e o desenho. $\mathrm{O}$ excerto diz:

Ouço uma frase de aranquã: ên-ên? ço-bô! abê ban? bum?...

Não tive preparatório em linguagem de aranquã.

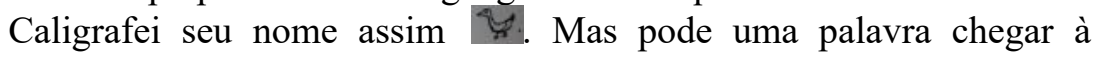
perfeição de se tornar um pássaro?

Antigamente podia.

As letras aceitavam pássaros.

As árvores serviam de alfabeto para os Gregos.

A letra mais bonita era a $¥$ (palmeira).

Garatujei meus pássaros até a última natureza.

Notei que descobrir novos lados de uma palavra era o mesmo que descobrir novos lados do Ser.

As paisagens comiam no meu olho.

Ao afirmar que não teve preparatório em língua de aranquã, o poeta se licencia a pôr em relação a caligrafia e o desenho, fazendo supor o desenho como a forma de representação mais precisa, perfeita, em relação à coisa representada: "caligrafei seu 
nome assim 4 . Mas pode uma palavra chegar à perfeição de se tornar um pássaro?" Tal é a maestria do escritor com a palavra que, ao explicitar o fenômeno que opera em seu procedimento de escrita, o de materializar na palavra a coisa dita, o faz substituindo o desenho/a imagem pela palavra. Ainda, sob o argumento de que para os gregos as letras tomavam a forma de pássaros, servindo como alfabeto, o escritor versa "A letra mais bonita era a $¥$ (palmeira)". Ou seja, o escritor revela o seu procedimento estético com a palavra escrita, que é o de fazer poesia buscando aproximações entre significantes, produzindo o efeito de uma relação entre palavra e coisa.

O poeta diz da relação entre significantes. É citação, glosa, referência de uma materialidade à outra, em que a fotografia e o bordado se projetam na escrita e em que a imagem faz supor a representação perfeita da coisa. O escritor se dispersa nos fios dessas materialidades significantes, desses dizeres, fazendo significar o Outro que o habita. Como vimos de Authier-Revuz (1990, p. 28), ao afirmar que "sempre sob as palavras, 'outras palavras' são ditas", de modo que as palavras são desde sempre do Outro.

\section{CHÃO POETA}

Sabiá com trevas Manoel de Barros

A literatura, como pensamos ancoradas em Foucault, vai se constituindo a partir de rituais que instauram uma memória da e na língua: memória na sintaxe (ALMEIDA, 2012), nas repetições; memória que dá forma e formato à escrita/texto; memória que se inscreve também nas bordas do texto delimitando-os e contendo-os: título, dedicatória, epígrafes, notas, e, entre outras bordas, glossários. Um ritual que inscreve o que pode estar dentro e o que pode/deve ser o fora do texto. Um ritual que se parte, que fura. Com o poema "Glossário de transnominações em que não se explicam algumas delas (nenhumas) ou menos" estamos diante desta quebra. Não se trata de um texto à parte, como é o caso dos glossários, mas de um glossário-poema ou poema-glossário que põe em foco a palavra: matéria-prima do poeta.

O poema em foco encontra-se no livro chamado Arranjos para assobio (1998) e em Poesia Completa / Manoel de Barros (2013). Compõe-se de onze verbetes, em itálico, sobre os quais se indicam classe gramatical e gênero, seguidos de ao menos quatro definições que aparecem encadeadas sob a forma de listas (umas abaixo das outras); ao final, um apêndice com três definições-verso, e, por fim, uma referência como nota do autor. É preciso vê-lo/lê-lo:

Glossário de transnominações em que não se explicam algumas delas (nenhumas) ou menos

Cisco, s.m.

Pessoa esbarrada em raiz de parede

Qualquer indivíduo adequado a lata

Quem ouve zoadas de brenha. Chamou-se de

O CISCO DE DEUS a São Francisco de Assis

Diz-se também de homem numa sarjeta 
Poesia, s.f.

Raiz de água larga no rosto da noite

Produto de uma pessoa inclinada a antro

Remanso que um riacho faz sob o caule da manhã

Espécie de réstia espantada que sai pelas frinchas de um homem

Designa também a armação de objetos lúdicos com emprego de

palavras imagens cores sons etc. - geralmente feitos por crianças

pessoas esquisitas loucos e bêbados

Lesma, s.f.

Semente molhada de caracol que se arrasta

sobre as pedras deixando um caminho de gosma escrito com o

corpo

Indivíduo que experimenta a lascívia do ínfimo

Aquele que viça de líquenes no jardim

Boca, s.f.

Brasa verdejante que se usa em música

Lugar de um arroio haver sol

Espécie de orvalho cor de morango

Ave-nêspera!

Pequena abertura para o deserto

Água, s.f.

Da água é uma espécie de remanescente quem já incorreu

ou incorre em concha

Pessoas que ouvem com a boca no chão seus

rumores dormidos pertencem das águas

Se diz que no início eram somente elas

Depois é que veio o murmúrio dos corgos para dar

testemunho do nome de Deus

Poeta, s. e s.f.

Indivíduo que enxerga semente germinar e engole céu

Espécie de um vazadouro para contradições

Sabiá com trevas

Sujeito inviável: aberto aos desentendimentos como um rosto

Inseto, s.m.

Indivíduo com propensão a escória

Pessoa que se adquire da umidade*

Barata pela qual alguém se vê

Quem habita os próprios desvãos

Aqueles a quem Deus gratificou com a sensualidade

(vide Dostoievski, Os irmãos Karamazov)

Sol, s. m.

Quem tira a roupa da manhã e acendo o mar

Quem assanha as formigas e os touros

Diz-se que:

Se a mulher espiar o seu corpo num ribeiro

florescido de sol, sazona

Estar sol: o que a invenção de um verso contém 
Trapo, s.m.

Pessoa que tendo passado muito trabalho e fome

deambula com olhar de água suja no meio das ruínas

Quem as aves preferem para fazer seus ninhos

Diz-se também de quando um homem caminha para

nada

Pedra, s.f.

Pequeno sítio árido em que o lagarto de pernas

areientas medra (como à beira de um livro)

Indivíduo que tem nas ruínas prosperantes de sua

boca avidez de raiz

Designa o fim das águas e o restolho a que o homem

tende

Lugar de uma pessoa haver musgo

Palavra que certos poetas empregam para dar

concretude à solidão

Árvore, s.f.

Gente que despetala

Possessão de insetos

Aquilo que ensina de chão

Diz-se de alguém com resina e falenas

Algumas pessoas em quem o desejo

é capaz de irromper sobre o lábio

como se fosse a raiz de seu canto

Apêndice:

Olho é uma coisa que participa o silêncio dos outros

Coisa é uma pessoa que termina como sílaba

O chão é um ensino.

* - Eu te levanto da umidade, inseto! Invectiva do folclore pantaneiro colhida por Leonardo Leite de Barros (N. do A.)

Letra, caligrafia, desenho, bordado, fotografia são algumas das materialidades simbólicas que se fazem poesia em Manoel de Barros, como já dissemos. No poema, o glossário se faz poesia listando definições e, com elas, se descolam e deslocam sentidos, instauram-se outras polissemias, desfazem-se lugares já estabelecidos por uma dicotomia entre o que seria humano e o que seria natureza - "Cisco. Pessoa esbarrada em raiz de parede; Árvore. Gente que despetala." - Aqui, nada é dicotômico. "É vazadouro; é desentendimento". É deslocamento. "Réstia espantada; brasa verdejante que se usa em música". É contraste; contradição. "Lascívia do ínfimo; sabiá com trevas". As definiçõesverso não se pontuam, não se esgotam; permanecem suspensas como à espera de outras no vão que se abre entre os blocos num jogo infinito do definir indefinindo.

No poema, insiste-se numa metalinguagem em que todos os termos são substantivos, marcados somente pelo gênero. Cisco, Poesia, Lesma, Boca, Água, Poeta, Inseto, Sol, Trapo, Pedra, Arvore. A palavra é substantiva: substância do poeta, substância do glossário. Nela poeta e lexicógrafo encontram-se em sua paixão/prazer pela palavra. Com a palavra se brinca também no modo como se introduzem as definições no dicionários e glossários: seja no gozo jocoso das assertivas - "Produto de pessoa inclinada a antro; Lugar de arroio haver sol; Barata pela qual alguém se vê; Possessão de insetos" 
-, no espanto da definição - "Ave-nêspera!" -, ou ainda no jogo com os enunciadosdefinitórios ${ }^{7}$ - "Diz-se também de homem numa sarjeta; Indivíduo que experimenta a lascívia do ínfimo; Designa o fim das águas e o restolho a que o homem tende; Aquele que viça de líquenes no jardim". Se a definição tece uma relação entre um significante tomado como signo autônimo (como verbete) e significado que com ela, definição, se constrói, o jogo aqui é expor sua trapaça, ou ainda, a ilusão da fórmula $\mathrm{X}=\mathrm{Y}$ em espaços logicamente estabilizados (PECHEUX, 1990b, p. 31).

O poema transborda em nota: "Pessoa que se adquire da umidade*/ - Eu te levanto da umidade, inseto! Invectiva do folclore pantaneiro colhida por Leonardo Leite de Barros (N.do A.)". Sobre as notas, Orlandi (1990) nos avisa que denunciam a não-linearidade do sentido e constituem sintomas da incompletude do texto. Espaço de um dizer a mais na ilusão de tudo dizer e de com ele o dizer se bastar. A nota, nos aponta Compagnon (1996, p. 84) na mesma clave, "não permite nenhum retorno, nenhum remorso, nenhuma repetição: com ela, tudo está dito". Na nota do poema comparece o exemplo com a respectiva fonte outra - "colhida por Leonardo Leite de Barros" - que produz o efeito de atestação do sentido num movimento, diríamos, borgeano ou ainda roseano, de dar veracidade ao dizer/fazer escrita no jogo da indicação/criação de fontes várias, no uso jocoso do discurso da ciência que nelas se ancora. Compagnon nos sussurra: a nota "proíbe o recurso, é o selo ou carimbo que garante a autenticidade do texto, seu acabamento; e assinatura do autor" (idem). Nosso poeta assina: "(N. do A.)".

Do glossário-poema, o apêndice faz parte: interno ao corpo, inscrito na memória do dicionário que se apresenta na sintaxe que faz equivaler desiguais (X é Y); sintaxeassinatura do lexicógrafo-poeta que aí diz: "Olho é uma coisa que participa o silêncio dos outros; Coisa é uma pessoa que termina como sílaba; O chão é um ensino." Três substantivos-substâncias: olho, coisa, chão. Olho que remete para coisa. Coisa que remete para pessoa. Corte para chão, ensino. $\mathrm{O}$ chão é um ensino. Ponto final denunciando o chão como ponto, parada e ensino.

Com o poema (des)acordam-se, enfim, imagens, sonoridades, sintaxes e sentidos no gesto do ir além do já posto/suposto, na captura do significante que, no jogo do gesto glossarístico, se transmuda e se esgarça para outros sítios de significância, denunciando a trapaça da palavra como signo e nos lembrando que sob as palavras muito se diz à despeito do suposto domínio do falante.

Das notas, glossários e apêndices talvez se possa dizer que funcionam na duplicidade contraditória do supérfluo (porque à parte) / necessário (porque a mais). Partes que assombram o texto suposto como unidade - princípio, meio e fim - e que denunciam seu real: um (a se) fazer que não se fecha e que não se inicia na letra que abre o texto. Em outras palavras, seguindo Orlandi (1987), estamos recuperando o texto como objeto discursivo, com espessura histórica, memória que apaga o trabalho sobre ele, sobre a língua, sobre o outro/Outro, apagamento que estas bordas deixam entrever. Aí também reside o blefe neste poema ao trazer tais partes como material simbólico para poesia.

\footnotetext{
7 Estamos considerando como enunciado-fórmula aqueles que servem a uma escrita definitória no dicionário e que, deste modo, trabalham uma impessoalidade e cientificidade deste instrumento linguístico, conferindo positividade àquilo que será predicado após o verbete (MEDEIROS, 2014). Servem como enunciados-fórmula: diz-se que, aquele que, designa....
} 


\section{AINDA CHÃO}

Pequena abertura para o deserto Manoel de Barros

Todo discurso, podemos dizer seguindo Authier-Revuz (2007), constrói-se no jogo de forças com o discurso Outro que o constitui, na negociação necessária com a heterogeneidade constitutiva, que se denuncia nos pontos de não-coincidência do dizer (lugares em que a negociação se mostra). Se recuperamos com Auroux (1992) a historicidade do glossário, diríamos que este se funda na não-coincidência interlocutiva de que fala Authier (1998, p. 192) - aquela que, com bases teóricas pós-freudiana, é colocada como constitutiva da enunciação, isto é, aquela em que se inscreve a interlocução, considerando os sujeitos como radicalmente não simetrizáveis pelo fato do inconsciente - e no jogo inevitável da nomeação que instaura uma predicação (isto se chama $\mathrm{X}$ ) que retorna ao nome e produz $\mathrm{X}$ é isto. E assim tem-se um outro efeito/ilusão - da relação entre as palavras e as coisas - que escamoteia a não-coincidência entre as palavras e as coisas (idem, p. 194).

Sobre o glossário-poema do nosso poeta ousamos dizer que troça com estes efeitos e ilusões construindo-se na ludicidade que assume a equivocidade dos sentidos, na equivocidade da língua acenando a lalangue - nas palavras de Milner (1987, p. 15), "o que faz com que uma língua não seja comparável a nenhuma outra" -, na equivocidade que, novamente com Milner (1987, p. 13), "promove a homofonia, homossemia, homografia, tudo o que suporta outros sentidos, que admite o éter da língua".

“Avidez de raiz", nos avisa o poeta.

\section{REFERÊNCIAS}

ALMEIDA, E. Cabeludinho: Língua, sujeito e nação. Em: ALMEIDA, E.; PAROLIN, M.I. (Org.). Fronteiras de sentidos e sujeito nacionais. Campinas: RG, 2012.

AUTHIER-REVUZ, J. Palavras Incertas. Campinas: Ed. da Unicamp, 1998. . Heterogeneidade(s) enunciativa(s). Caderno de Estudos Linguísticos, 19, 1990.

AUROUX, S. A filosofia da linguagem. Campinas: Editora da Unicamp, 1998. . A revolução tecnológica da gramatização. Campinas: Ed. da Unicamp, 1992.

BARROS, M. de. Glossário de transnominações em que não se explicam algumas delas (nenhumas) ou menos. [Manoel de Barros, Poesia Completa]. São Paulo: Leya, 2014.

. Memórias Inventadas: a terceira infância. São Paulo: Editora Planeta, 2008.

Memórias Inventadas: a segunda infância. São Paulo: Editora Planeta, 2006.

Memórias Inventadas: a infância. São Paulo: Editora Planeta, 2003.

. Exercícios de ser criança. Bordados de Antônia Zulma Diniz, Ângela, Marilu, Martha e

Sávia Dumont sobre desenhos de Demóstenes Vargas. Rio de Janeiro: Editora Salamandra, 1999. . Arranjos para assobio. Rio de Janeiro: Record, 1998.

. Gramática expositiva do chão. Rio de Janeiro: Civilização Brasileira, 1990.

COMPAGNON, A. O trabalho da citação. Belo Horizonte: Ed. da UFMG, 1996.

DUBOIS, J. et. al. Dicionário de Linguística. São Paulo: Cultrix, 1991.

FOUCAULT, M. Estética: literatura e pintura, música e cinema. [Coleção Ditos \& Escritos III]. Rio de Janeiro: Forense, 2006.

. A ordem do discurso. São Paulo: Edições Loyola, 1996. 
Linguagem e Literatura. Em: MACHADO, R. Foucault, a filosofia e a literatura. Rio de Janeiro: Jorge Zahar Editor, 2005.

LEMOS, C.T.G. de. Poética e significante. Letras \& Letras, 25, Uberlândia, 2009.

MEDEIROS, V. Memória e singularidade no gesto do escritor-lexicógrafo. Confluências, Rio de Janeiro, n. 46, 2014.

MILNER, Jean-Claude. O amor da língua. Porto Alegre: Artes Médicas, 1987.

ORLANDI, E.P. Un point c'est tout. Interdiscours, incomplètude, textualisatoin. In: AUTHIERREVUZ, J.; LALA, M.-C. (Dirs.). Figures d'ajout: phrase, texte, écriture. Paris: PSN, 2007.

. Reflexões sobre escrita, educação indígena e sociedade. Escritos, n. 5, Escrita, Escritura, $\overline{C i d a d}$, Laboratório de Estudos Urbanos, Nudecri, Campinas, 1999.

. Terra à Vista. São Paulo: Cortez, 1990.

. A produção da leitura e suas condições. Em: A linguagem e seu funcionamento. $2^{\mathrm{a}}$. ed. Campinas: Pontes, 1987.

PÊCHEUX, M. Ler o arquivo hoje. Em: ORLANDI, E.P. (Orgs.). Gestos de leitura: da história no discurso. Trad. Bras. Campinas: Ed. da Unicamp, 1997.

Delimitações, inversões, deslocamentos. Cadernos de Estudos Linguísticos, n. 19, 7-24, Unicamp, Campinas, 1990a.

. O discurso: estrutura ou acontecimento. Campinas: Pontes, $1990 \mathrm{~b}$.

Artigo recebido em: abril de 2018.

Aprovado e revisado em: agosto de 2018.

Publicado em: dezembro de 2018.

\section{Para citar este texto:}

ALMEIDA, Eliana de; MEDEIROS, Vanise. A língua na língua do poeta: o próprio da língua. Entremeios [Revista de Estudos do Discurso, ISSN 2179-3514, on-line, www.entremeios.inf.br], Seção Temática [Discurso, arte e literatura - Parte II], Programa de Pós-Graduação em Ciências da Linguagem (PPGCL), Universidade do Vale do Sapucaí (UNIVÁS), Pouso Alegre (MG), vol. 17, p. 263-276, jul. - dez. 2018.

DOI: http://dx.doi.org/10.20337/ISSN2179-3514revistaENTREMEIOSvol17pagina263a276 